\title{
Egg-spot matching in common cuckoo parasitism of the oriental reed warbler: effects of host nest availability and egg rejection
}

\author{
Donglai $\mathrm{Li}^{1 \dagger}$, Yanan Ruan ${ }^{1 \dagger}$, Ying Wang ${ }^{1}$, Alan K. Chang ${ }^{1}$, Dongmei Wan ${ }^{1 *}$ and Zhengwang Zhang ${ }^{2}$
}

\begin{abstract}
Background: The success of cuckoo parasitism is thought to depend largely on the extent of egg matching between cuckoo and host eggs, since poor-matching cuckoo egg would lead to more frequent egg rejection by the host. In this study, we investigated how egg-spot matching between the Common Cuckoo (Cuculus canorus) and its host, the Oriental Reed Warbler (Acrocephalus orientalis) is affected by the local parasitism rate, nest availability in breeding synchronization and egg rejection.
\end{abstract}

Methods: We used the paired design of parasitized and their nearest non-parasitized nests where breeding occurred simultaneously to compare egg-spot matching. The image analysis was used to compare four eggshell pattern variables, namely spot size, density, coverage on the different areas of egg surface, and the distribution on the whole egg surface. Egg recognition experiments were conducted to test the effect of egg spots on egg rejection by the host.

Results: Our results show that much better matching in almost all spot parameters tested on the side of the egg and the spot distribution on the whole egg occurred in parasitized nests than in non-parasitized nests. Matching of spot density between cuckoo and host eggs in parasitized nests increased with the synchronization between temporal availability of nests and the egg-laying period of female cuckoos. Egg recognition experiments in which the warbler eggs were deliberately painted with extra spots led to a significantly higher egg rejection rate (78.3\%) than of unpainted eggs.

Conclusion: Our data suggest that both the high temporal encounter rate between cuckoo and warbler nests as well as the high egg rejection ability of the host are important factors for egg-spot matching of the cuckoos.

Keywords: Brood parasite, Cuckoo, Egg mimicry, Egg matching, Spot pattern, Egg rejection, Parasitism rate, Oriental Reed Warbler

\section{Background}

Mutual interactions between parasitic cuckoos and their hosts represent an outstanding textbook example of co-evolution (Rothstein 1990; Feeney et al. 2014). Such interactions have led to the evolution of many amazing biological phenomena (Davies 2011; Spottiswoode and Stevens 2012; Soler 2014). Among these, the remarkable

\footnotetext{
${ }^{*}$ Correspondence: lidonglaibnu@163.com

${ }^{\dagger}$ Donglai Li and Yanan Ruan contributed equally to this work

${ }^{1}$ Provincial Key Laboratory of Animal Resource and Epidemic

Disease Prevention, College of Life Sciences, Liaoning University,

Shenyang 110036, People's Republic of China

Full list of author information is available at the end of the article
}

resemblance in egg appearance (color and spot patterns) between cuckoos and their hosts, termed "mimicry", has long attracted the attention of behavioral ecologists (Chance 1940; Brooke and Davies 1991; Davies 2000; Igic et al. 2011). Although this phenomenon has been extensively studied, it has largely been explained as an evolutionary response to the strong egg rejection carried out by the host during their long co-evolutionary interaction (Brooke and Davies 1988; Soler et al. 2003; Stoddard and Stevens 2011; Avilés et al. 2012). However, the effect that active host-nest selection has on egg mimicry used by the cuckoo partner has not been conclusively demonstrated (see Avilés and Møller 2004). The Common 
Cuckoo (Cuculus canorus, hereafter "the cuckoo"), one of the most well studied obligate brood parasites, has many different egg phenotypes, called "gentes" or "races" that are distinguishable among each other and show hostspecific lineages (Moksnes and Røskaft 1995; Marchetti et al. 1998; Gibbs et al. 2000; Fossøy et al. 2011, 2016). The existence of these gentes is probably maintained by the tendency of the cuckoo to choose its host actively, as a result of host imprinting, a phenomenon that has previously been reported by various investigators (Wyllie 1981; Honza et al. 2001, 2002; Avilés and Møller 2004; Nakamura et al. 2005). However, how individual cuckoos specifically choose their hosts within a single species of birds, in particular following the matching between their own eggs and those of their hosts, has been a subject of great debate (Antonov et al. 2012; Yang et al. 2015b).

There are two hypotheses regarding whether the cuckoo can actively choose the host nests which bear eggs with similar appearance to its own eggs during parasitism. In recent years, several empirical studies have been conducted to investigate these two interesting hypotheses, but the results from these studies are rather ambiguous. The egg-matching hypothesis (EMH) suggests that the cuckoo lays eggs matching the appearance of the eggs of its host because the high rejection rate of poorly matched eggs would be costly to its breeding process (Avilés et al. 2006; Cherry et al. 2007; Feeney et al. 2012; Honza et al. 2014). Obviously, this egg-laying strategy would increase the possibility of egg acceptance by the hosts and improve the evolutionary progress of egg mimicry. However, it is still unclear if a female cuckoo can recognize its own egg phenotype and has the ability to choose the right nest out of the many nests it encounters and, if so, the problem arises whether there are always enough suitable nests (in the egg laying stage before incubation) available to be used within its breeding territory (Liang et al. 2016). The random egg-laying hypothesis (REH) states that brood parasites lay eggs randomly in host nests (Orians et al. 1989; Antonov et al. 2012), because its secretive and rapid egg-laying behavior limits the visual discrimination of their own egg appearance and that of the host eggs (Payne 1977; Yang et al. 2015b). Besides, it is very common for a cuckoo to lay eggs in the nests of the hosts that have different egg appearances (Moksnes and Røskaft 1995; Grim 2002). Recently, Yang et al. (2015b) have used a conceptual model to argue that the egg-matching egg-laying behavior is maladaptive in the case of the Common Cuckoo and its parrotbill hosts, both of which have evolved to lay distinctive polymorphic eggs. This phenomenon has further been confirmed in the Tailorbirds (Orthotomus sutorius), which are also randomly parasitized by Plaintive Cuckoos (Cacomantis merulinus), irrespective of the appearance of their eggs (Yang et al. 2015a).

Three empirical studies from Europe have shown that cuckoo eggs are more similar to the host eggs in naturally parasitized nests than in non-parasitized or randomly chosen nests, thereby providing support for the EMH (Avilés et al. 2006; Cherry et al. 2007; Honza et al. 2014). These studies have focused more on the background color of the eggs and less attention has been given to the spot pigment and pattern of the eggs. However, recent studies (Antonov et al. 2012; Šulc et al. 2016; Yang et al. 2016), which focused on the cuckoo hosts, the Marsh Warbler (Acrocephalus palustris), the Great Reed Warbler (A. arundinaceus) and the Oriental Reed Warbler (A. orientalis), have found no support for the EMH, despite the inclusion of egg-spot traits. Several studies have suggested that egg color is a more important recognition cue than spot patterns (Moskát et al. 2008; Spottiswoode and Stevens 2010). However, relative to egg color, the spottiness of the egg is thought to have a greater variation and is more distinctive and complex, thus having more recognizable signatures that are more likely to be involved in egg recognition carried out by the hosts (Øien et al. 1995; Kilner 2006; Underwood and Sealy 2006; Stoddard and Stevens 2010; Spottiswoode and Stevens 2012; Medina et al. 2016).

From these studies, it can be concluded that the two hypotheses might not be mutually exclusive. Recently, one model study has shown that both EMH and REH are valid for cuckoo parasitism in the presence of egg polymorphism (Liang et al. 2016). The choice of which egglaying strategy would be adopted can be determined by many ecological and evolutionary changes, both in the cuckoo and its host, but most of these have largely been neglected in previous studies. Two critical factors known to determine which strategy is optimal are the rate of encounter with the host nests and the level of egg rejection achieved by the host (Liang et al. 2016). The parasitism rate can partly reflect the rate of encounter with host nests (population density of cuckoo and/or the availability of host nests) (Stokke et al. 2007), but this parameter is rarely used to investigate its effect on the egg-laying strategy of cuckoos (but see Soler et al. 2015). In addition, the same cuckoo, either as an individual bird or as a population, may also shift the choice of egg-laying strategy following the temporal availability of host nests vulnerable to parasitism.

The Oriental Reed Warbler (Acrocephaus orientalis) is frequently parasitized by the Common Cuckoo in eastern China (Liang et al. 2014; Yang et al. 2014), where both species lay dark, brown-spotted eggs (Li et al. 2016). We used egg spots as the main feature to investigate the 
phenomenon of egg matching between cuckoo and warbler and its effect on egg rejection conducted by the warbler. We speculated that cuckoos may choose the EMH egg-laying strategy if the egg spots can act as a significant signature that decides whether the egg is accepted or rejected by the warbler, or whether there is a high availability of suitable host nests at the time the cuckoo lays its egg. Furthermore, we also hypothesized that egg-spot matching between cuckoo and warblers would increase with more nest synchronization at the cuckoo egg-laying stage, if the cuckoos temporally fine tune their egg-laying strategy to EMH or REH within one breeding season. We also discuss other factors that may affect the choice of alternative strategies.

\section{Methods}

\section{Study site and field measurements}

Field work was carried out during the breeding season (late May to July) in 2013-2015, at the Liaohe Delta Nature Reserve $\left(41.033929^{\circ} \mathrm{N} ; 121.725244^{\circ} \mathrm{E}\right)$, Liaoning Province, northeastern China. This region has a semiarid continental monsoon climate with rainfall usually occurring in late July to September. The delta is one of the most important estuarine wetlands in the coastal region of China, with the largest area of Phragmites reed fields $\left(800 \mathrm{~km}^{2}\right)$ in northeastern Asia. These Phragmites wetlands are extensively used for culturing Chinese Mitten Crabs (Eriocheir sinensis) and for the production of reed biomass used in the paper industry. As well, energy projects are being constructed in these wetlands because of the oil fields they contain. The associated oil field infrastructures have led to the installation of electrical wires, which provide perch sites for the cuckoos. Significant growth of these wetlands is found along the edge of the reed fields along ditches, which have become a suitable nesting place for the Oriental Reed Warblers (hereafter "the warbler"). The warbler is the dominant host for the cuckoo in this area. Both the cuckoo and warbler are migrant birds. They come to breed in these wetlands in large numbers during late May to early June. The breeding season lasts till early August.

We systematically searched for nests of warblers at three main reed fields $(<5 \mathrm{~km}$ between each site), where the warblers breed in high densities. After a nest was found, its location was recorded with a Garmin GPS 60s. Almost all the nests were found during the nest-building or egg-laying stage and were checked daily until clutch completion. During each check, every newly laid egg was numbered using a felt tip pen to allow the identification of missing eggs. To investigate whether the cuckoos would actively choose between nests that are equally accessible, we used the paired design of parasitized and their nearest non-parasitized nests where breeding occurred simultaneously (i.e., the interval of egg-laying dates is $\leq 5$ days) with the distance between the two nests less than $150 \mathrm{~m}$ (Antonov et al. 2012; Yang et al. 2016). These criteria were chosen because the warbler has a typical clutch size of five eggs and is most often parasitized during the 5-day egg-laying stage. The warbler lays one egg per day at dawn and previous video recordings have confirmed that female cuckoos tend to remove one warbler egg from the nest that they parasitize $(n=7$; Li et al. unpublished data), which is similar to the laying behavior of the Common Cuckoo in Europe (Davies and Brooke 1988). To enable the correct assignment of the parasitism status, only nests found during the nest-building or early egg-laying stage (1-2 eggs) were included (Antonov et al. 2012). These nests were monitored daily until clutch completion. One cuckoo egg was found to be rejected four days after it was laid. Fortunately, this nest was photographed before the egg was ejected and used in the analysis. The rejection rate (including nest desertion) of cuckoo eggs was lower than $9 \%(n=35)$ according to our previous unpublished data, a much lower rate than the $26.9 \%$ reported for the Great Reed Warbler in Europe (Kleven et al. 2004). No marked warbler eggs were missing except for two non-parasitized nests in which the missing marked eggs were exchanged with cuckoo eggs during the monitoring period and were therefore excluded from the analysis. Only nests parasitized by one cuckoo egg were used in our study. Subsequently, all the eggs of two clutches within a pair were photographed (Cannon D70 camera) in a standard way on a Kodak grey plate. In order to show the spot distribution on the entire egg, we photographed the spot distribution on the blunt and pointy ends as well as on the side of the egg (see Fig. 1). During the taking of photographs, we used a blind method to ensure a random side of the eggs was shown (Yang and Liang 2016).

\section{Egg-spot measurements}

All the egg photographs were processed using the ImageJ software (version $1.45 \mathrm{~s}$, http://imagej.nih.gov/ij). These images were first balanced according to a white standard on the color scale and then the areas containing the egg images were cropped and scaled. We used Bernsen's threshold method to convert the images into a binary (black/white) format, with black pixels corresponding to the egg spots and white pixels to the background egg color (Landini 2011). Circular frames were selected to represent the blunt and pointy ends of the egg whereas an ellipse frame was selected to represent the side of the egg. Only about half of the visible area photographed in the central part of the egg was selected for subsequent spot pattern analyses, because the margin of the image could be biased due to the curvature of the egg 

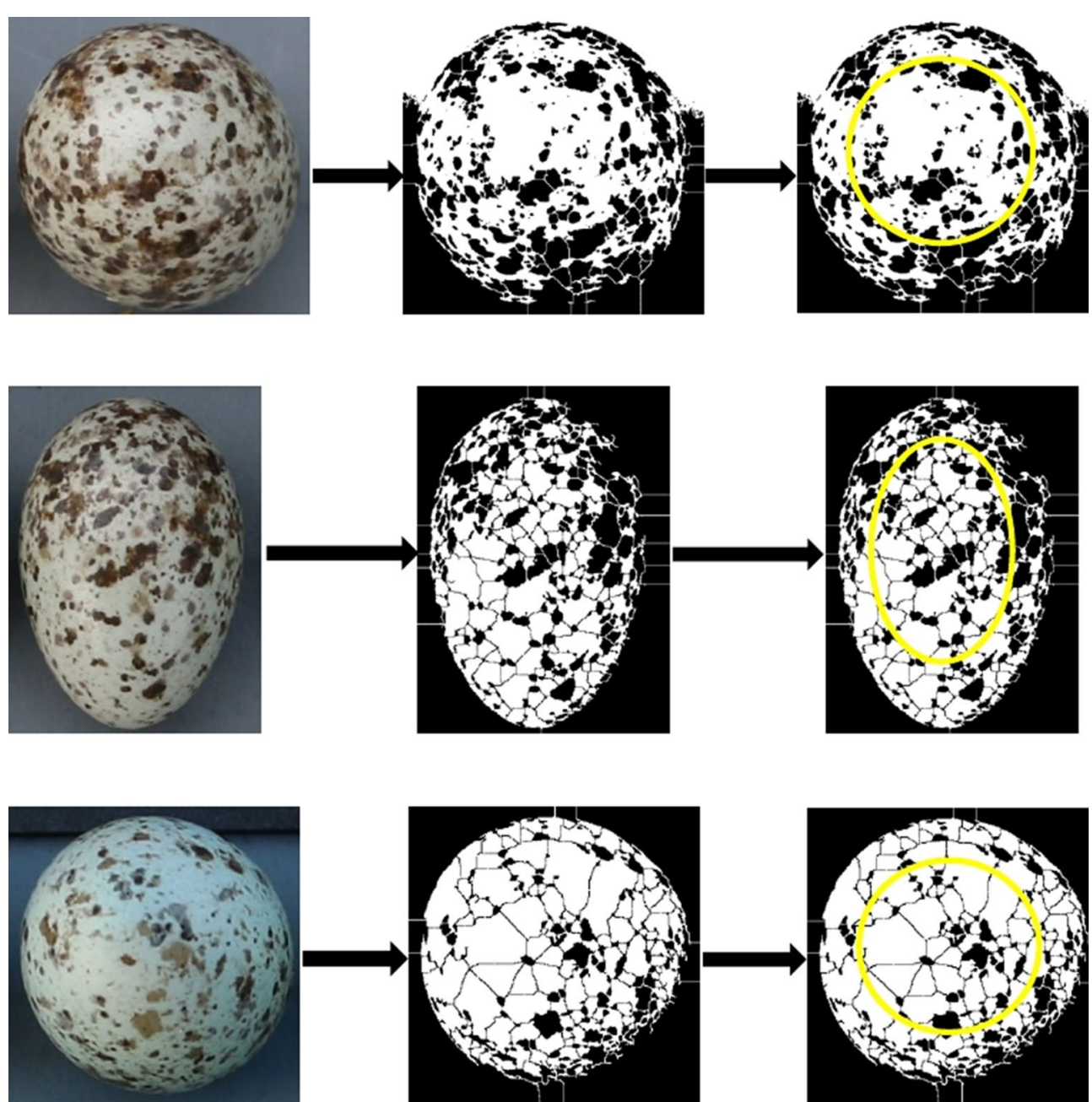

Fig. 1 Egg-spot pattern as viewed from different angles of the egg. The black and white images were obtained with the ImageJ software. The region on the egg enclosed by yellow circle represents about half the visible area used in the analysis

and unequal shading (Šulc et al. 2016). According to the protocol in Antonov et al. (2012), we extracted four variables for the spot patterns: (1) spot size $\left(\mathrm{mm}^{2}\right)$-the average value for all spots within the selected frame; (2) spot density (number of spots $/ \mathrm{mm}^{2}$ )-number of spots per unit area; (3) spot coverage (\%) - percentage area of the egg covered by spots; (4) spot distribution-proportion of spot coverage at the blunt end. Finally, the absolute differences among the four spotting-pattern variables were calculated for each cuckoo egg in relation to the host eggs of the parasitized and non-parasitized nests and used as indices of contrast. We used two methods to compare the spot contrast between parasitized and non-parasitized nests. First, the method used by Antonov et al. (2012) was adopted, in which one random host egg was selected from each nest in the blind method and the difference between this egg and the cuckoo egg was assessed.
To avoid a potential deficiency in the method used by Antonov et al. (2012), which is caused by intra-clutch variation of the host eggs, a similar assessment to that reported by Yang et al. (2016) was also performed, but the average value of the whole clutch was used instead of the average value of a single egg.

\section{Egg recognition experiments}

Several studies have pointed out the significance of the effect of spot pattern on egg recognition by the hosts (Hauber et al. 2006; Moskát et al. 2008, 2014). Therefore, we also conducted egg recognition experiments to confirm the importance of spot matching in this cuckoowarbler system. We used 43 non-parasitized host nests in this study and randomly divided them into two groups in 2014-2015. In the experimental group, one host egg from the experimental nest was randomly chosen after the 
whole clutch had been laid. Ten extra dark brown spots, each about 3-4 $\mathrm{mm}$ in diameter, were then marked on the chosen egg using a brown fiber pen, which produced a similar natural dark spot color to that of the existing spots (Additional file 1: Fig. S1). In the control group, one egg was also randomly selected and manipulated in the same manner, but the egg was only marked with a number signature using a black water-proof pen. The nests were checked either daily or every second day. When the marked egg in the nest was missing within six days, it was assumed to be the result of rejection, whereas if the marked egg was still incubated in the nest at this time, it was considered as accepted by the host (Moksnes et al. 1991). No nest desertion was discovered, and nests that were predated during the six days were omitted.

\section{Data manipulation and statistical analyses}

The parasitism rate was presented as the percentage of nests found to contain cuckoo eggs or chicks. The first egg-laying date was recorded during the daily nest-checks or back-calculated from the number of eggs laid. The distance between nests as well as the distance from the nests to the nearest cuckoo perches (i.e., electric wires) were measured by the GoodyGIS (version 3.24) using the GPS location data of the nests. As suggested by Honza et al. (2014), it is really difficult to determine the home range at which a particular female cuckoo would lay egg; previous studies have revealed equivocal evidence for an exclusive territorial defense by female cuckoos. Thus we viewed all nests with similar egg-laying timing as nest availability to assess the potential encounter rate at which the cuckoo encountered its host nest when the cuckoo laid its egg. The potential host nests that were readily accessible to cuckoo parasitism were determined by tabulating the number of nests with the egg-laying phase commencing within five days before the cuckoo laid its egg, because the typical clutch size of the warbler is five eggs and they are most frequently parasitized by cuckoos in this period.

Chi square tests were used to compare the annual variation in parasitism rates and egg rejection rates by the host among groups. The differences in the first egg-laying date, the distance to perch site and the contrast in the spot pattern between parasitized and non-parasitized nests were compared using paired sample $t$-tests when normalization of the data was obtained. Otherwise, Wilcoxon signed rank tests were employed. We used independent two sample $t$-tests to compare the number of nests with synchronized egg-laying between the parasitized nests used for spot assessment and parasitized nests that were not assessed. Linear regression was used to explore the relationship between the spot contrast index (between cuckoo and warbler eggs) in the parasitized nests and nest availability with similar egg-laying dates. All statistical analyses were performed with Sigmaplot version 11.0. Data were presented as mean $\pm \mathrm{SE}$ and statistical significances were considered at the $p<0.05$ level.

\section{Results \\ Parasitism rates and sample size for measurement of egg spots}

The local cuckoo parasitism rate on the warbler was $16.6 \%$ ( $n=373$, range 14.7-18.6\%), without evidence of an annual fluctuation (Chi square test: $\chi^{2}=0.815, \mathrm{df}=2$, $p=0.665$; Additional file 2: Table S1). Only $1.3 \%(n=373)$ of the nests were parasitized by two cuckoo eggs, with an annual variation of one to two nests. According to a strict paired design criterion, 39 pairs of parasitized and non-parasitized nests were successfully obtained, with an average distance, between two nests within each pair, of $53.2 \pm 5.1 \mathrm{~m}(8.8-147.4 \mathrm{~m})$. The average nest availability for the parasitized nests used for spot assessment was $28.46 \pm 2.48(\mathrm{SE})$, range 5-57 $(n=39)$, which did not differ significantly from the 23 parasitized nests that were not assessed (22.42 $\pm 2.57 ; t=1.61, \mathrm{df}=61, p=0.112)$. No significance differences were found between parasitized and non-parasitized nests, either in the starting egg-laying dates of the host (first egg-laying date for the hosts in parasitized vs. non-parasitized nests: date 1 is June $1 ; 11.62 \pm 6.85$ vs. $11.28 \pm 6.30 ; t=0.763$, $\mathrm{df}=38$, $p=0.450$ ) or in the distance to the nearest perch (parasitized vs. non-parasitized nests: $33.10 \pm 52.43$ vs. $40.53 \pm 61.51 ; Z=1.180, \mathrm{df}=38, p=0.241)$.

\section{Matching egg-spot patterns between cuckoos and their hosts}

Measurements taken for egg-spot parameters on the side of the egg revealed significantly smaller contrasts between cuckoo eggs and host eggs in parasitized nests than in non-parasitized nests, with respect to spot size and spot density, both from the one-egg (Fig. 2) and the whole clutch assessments (Additional file 3: Fig. S2). In spot coverage, the contrast between cuckoo and host eggs was also significant on the basis of one-egg assessment, but not statistically significant in the case of whole clutch assessment, although the contrast was still obvious. No significant contrasts between cuckoo and host eggs in terms of egg spots on the blunt and sharp ends of the eggs were found, either on the basis of one-egg or on whole clutch assessments (Table 1). In the case of spot distribution, both types of assessments revealed significantly smaller contrasts in the parasitized nests (Fig. 2; Additional file 3: Fig. S2).

\section{Relationship between egg-spot matching and temporal availability of host nests}

Spot density contrasts on the side $\left(F_{1,37}=7.44\right.$, $p=0.010)$, blunt $\left(F_{1,37}=9.21, p=0.004\right)$ and sharp 

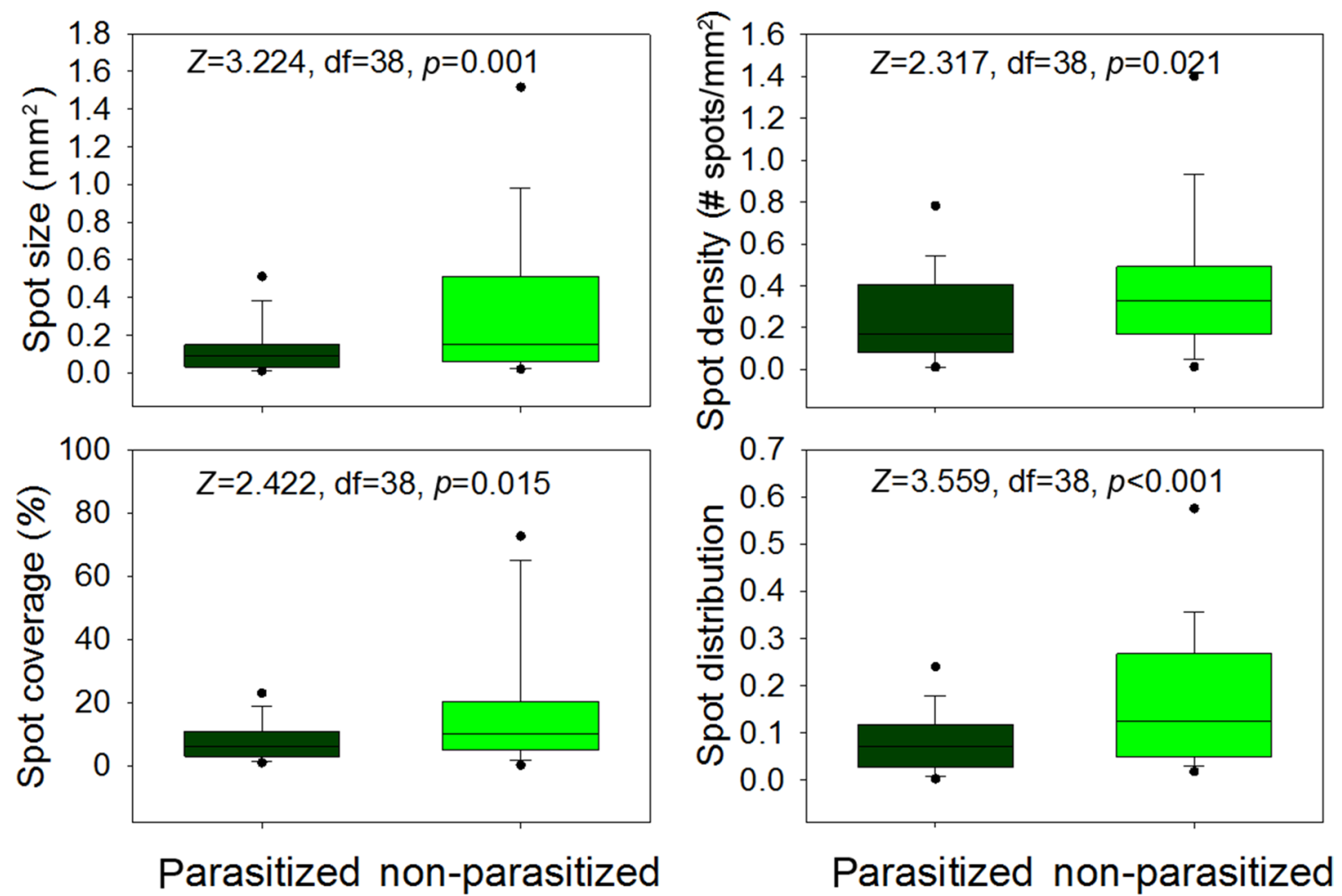

Fig. 2 Comparison of egg-spot matching between cuckoo and host eggs in parasitized and nearest non-parasitized nests. The plots show the medians, quartiles, 5th and 95th percentiles of the spot contrasts. Only results for the one-egg assessment are presented. The data from the wholeclutch assessment yielded similar conclusions and are therefore shown as supplementary material

Table 1 Comparison of egg-spot (spot size, spot density, spot coverage and sport distribution) matching between cuckoo and warbler eggs in naturally parasitized nests and their nearest non-parasitized nests

\begin{tabular}{|c|c|c|c|c|c|}
\hline Assessment method & Egg section & Variable & Parasitized & Non-parasitized & Statistics \\
\hline \multirow[t]{6}{*}{ One-egg assessment } & \multirow[t]{3}{*}{ Sharp } & Spot size $\left(\mathrm{mm}^{2}\right)$ & $0.21 \pm 0.18$ & $0.17 \pm 0.19$ & $t=1.308, \mathrm{df}=38, p=0.199$ \\
\hline & & Spot density (No. of spots $/ \mathrm{mm}^{2}$ ) & $0.37 \pm 0.47$ & $0.48 \pm 0.66$ & $Z=0.865, \mathrm{df}=38, p=0.391$ \\
\hline & & Spot coverage (\%) & $17.37 \pm 11.38$ & $17.84 \pm 14.98$ & $t=0.163, \mathrm{df}=38, p=0.871$ \\
\hline & \multirow[t]{3}{*}{ Blunt } & Spot size $\left(\mathrm{mm}^{2}\right)$ & $0.10 \pm 0.14$ & $0.24 \pm 0.49$ & $Z=1.283, \mathrm{df}=38, p=0.202$ \\
\hline & & Spot density (No. of spots $/ \mathrm{mm}^{2}$ ) & $0.37 \pm 0.43$ & $0.42 \pm 0.40$ & $Z=1.284, \mathrm{df}=38, p=0.202$ \\
\hline & & Spot coverage (\%) & $8.46 \pm 8.70$ & $12.61 \pm 20.43$ & $Z=1.102, \mathrm{df}=38, p=0.273$ \\
\hline \multirow[t]{6}{*}{ The whole clutch assessment } & \multirow[t]{3}{*}{ Sharp } & Spot size $\left(\mathrm{mm}^{2}\right)$ & $0.21 \pm 0.18$ & $0.17 \pm 0.19$ & $t=1.321, \mathrm{df}=38, p=0.194$ \\
\hline & & Spot density (No. of spots $/ \mathrm{mm}^{2}$ ) & $0.36 \pm 0.39$ & $0.43 \pm 0.62$ & $Z=0.670, d f=38, p=0.507$ \\
\hline & & Spot coverage (\%) & $17.26 \pm 11.45$ & $16.99 \pm 14.20$ & $t=0.107, \mathrm{df}=38, p=0.916$ \\
\hline & \multirow[t]{3}{*}{ Blunt } & Spot size $\left(\mathrm{mm}^{2}\right)$ & $0.07 \pm 0.08$ & $0.20 \pm 0.39$ & $Z=1.493, \mathrm{df}=38, p=0.137$ \\
\hline & & Spot density (No. of spots $/ \mathrm{mm}^{2}$ ) & $0.45 \pm 0.66$ & $0.40 \pm 0.39$ & $Z=0.670, d f=38, p=0.507$ \\
\hline & & Spot cover (\%) & $8.86 \pm 12.77$ & $12.20 \pm 19.36$ & $Z=1.109, \mathrm{df}=38, p=0.273$ \\
\hline
\end{tabular}

Only assessments on the sharp and blunt end of the egg are shown. Data are means $\pm \operatorname{SEs}(n=39)$

$\left(F_{1,37}=0.353, p=0.028\right)$ ends of the egg between cuckoo and warbler parasitized nests were negatively correlated with nest availability in the one-egg assessment (Fig. 3; Table 2). Similarly, a negative correlation was also observed for the other spot contrasts on the side of the egg in the one-egg assessment, but the correlation was not significant (Fig. 3). Similar results were also obtained for the whole-clutch assessment, with spot density contrasts between cuckoo eggs and warbler eggs in the parasitized nests negatively correlated with nest availability 

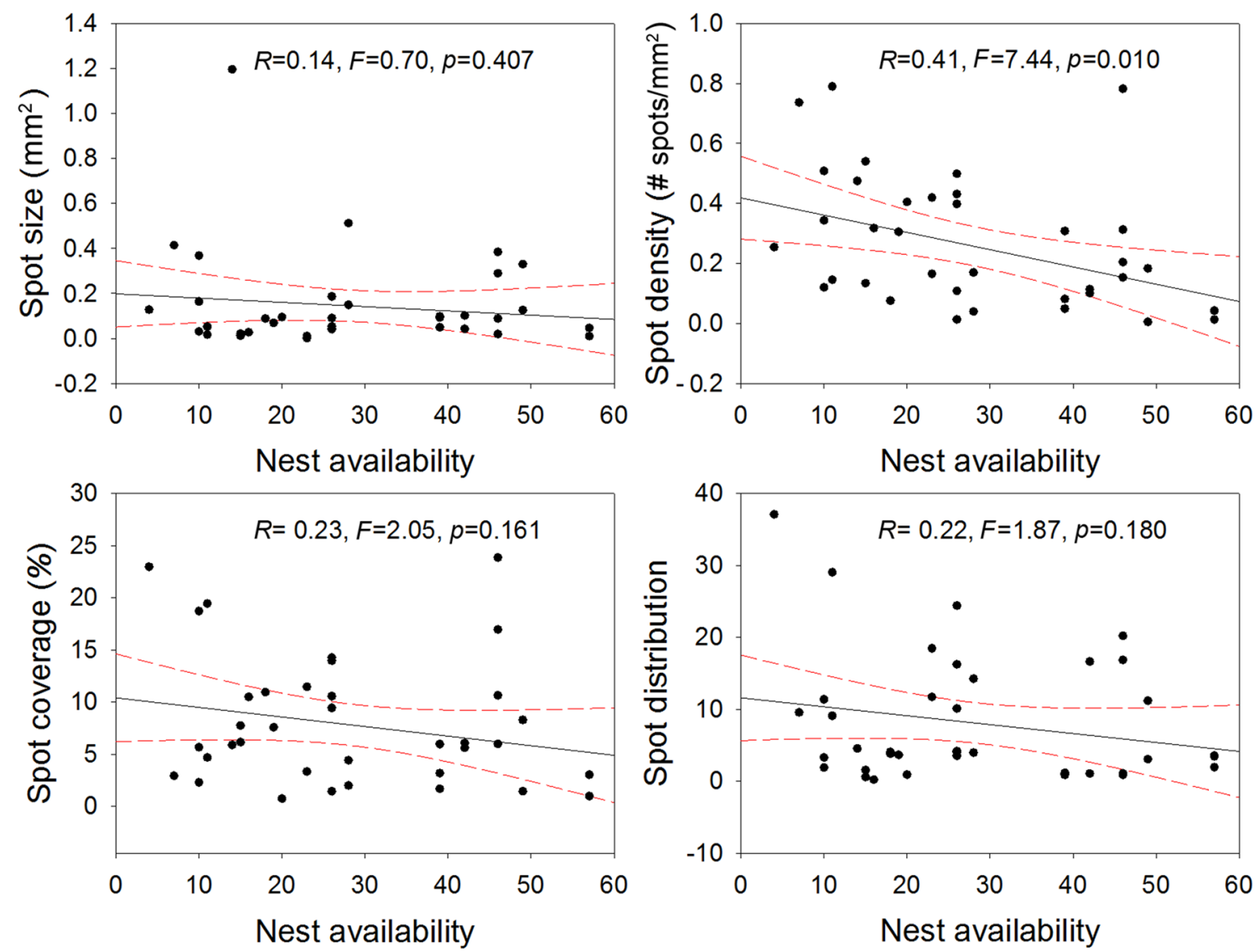

Fig. 3 Correlation between egg-spot matching (between cuckoo and warbler eggs) in parasitized nests and availability of host nests, synchronized with cuckoo egg-laying. The data represent spot contrasts. The solid and dashed lines show linear regressions and their $95 \%$ confidence intervals, respectively. Only results for the one-egg assessment are presented. Data from the whole clutch assessment yielded the same conclusion and are shown as supplementary materials

on the side $\left(F_{1,37}=7.53, p=0.009\right)$ and blunt end of the egg $\left(F_{1,37}=4.26, p=0.046\right)$, but not on the sharp end of the egg $\left(F_{1,37}=2.87, p=0.099\right)$. Additional information can be found in Additional file 4: Fig. S3 and Table 2.

\section{Effect of egg spots on the rejection rate by hosts}

The egg-rejection rate in the nests that contained the warbler egg painted with ten extra brown spots was $78.3 \%(n=23)$, which was significantly higher than that in the control group $\left(0 \%, n=20 ; \chi^{2}=23.8, \mathrm{df}=1\right.$, $p<0.0001)$. All the spotted eggs were ejected with no loss and damage to the unmarked eggs.

\section{Discussion}

Our study has revealed partial, but clear evidence supporting the presence of better egg-matching in spot patterns (spot size, spot density, spot coverage and spot distribution) between cuckoo and warbler eggs in parasitized nests than in non-parasitized nests, despite some deficiencies in the methodology and the hypothesis itself, such as the fact that cuckoos generally peck one or more host eggs during parasitism, while they have no opportunity to assess the whole-clutch (see discussion in Yang et al. 2016). The study has also provided large amounts of important experimental data in attempting to clarify the mixed and contrasting hypotheses on cuckoo eggmatching laying behavior. Previous studies conducted by Antonov et al. (2012) and Yang et al. (2016) on cuckoos have found no support for the EMH based on eggspot matching. Several factors may have accounted for the different outcomes in these studies. First, although we all used similar paired designs, Antonov et al. (2012) obtained their results based only on a comparison with the randomly selected host egg rather than the whole clutch. Second, Yang et al. (2016) compared the overall egg-spot pattern using the Nature-Pattern-Match (NPM) model developed by Stoddard et al. (2014) rather than specific aspects of the egg-spot pattern as in our case. 
Table 2 Correlation between egg-spot matching (between cuckoo and warbler eggs) in parasitized nests and availability of host nests synchronized with cuckoo egg-laying

\begin{tabular}{|c|c|c|c|c|c|c|}
\hline Assessment method & Egg section & Variables & Linear regression equation & $R$ & $F$ & $p$ \\
\hline \multirow[t]{10}{*}{ One-egg assessment } & \multirow[t]{3}{*}{ Side } & Spot size $\left(\mathrm{mm}^{2}\right)$ & $\begin{array}{l}\text { Spot size }=0.198-(0.00189 \times \text { nest } \\
\text { availability })\end{array}$ & 0.137 & 0.704 & 0.407 \\
\hline & & $\begin{array}{l}\text { Spot density (No. of spots/ } \\
\mathrm{mm}^{2} \text { ) }\end{array}$ & $\begin{array}{l}\text { Spot density }=0.418-(0.00575 \times \text { nest } \\
\text { availability })\end{array}$ & 0.409 & 7.436 & 0.01 \\
\hline & & Spot coverage (\%) & $\begin{array}{l}\text { Spot coverage }=10.412-(0.0918 \times \text { nest } \\
\text { availability })\end{array}$ & 0.229 & 2.048 & 0.161 \\
\hline & \multirow[t]{3}{*}{ Sharp } & Spot size $\left(\mathrm{mm}^{2}\right)$ & $\begin{array}{l}\text { Spot size }=0.168+(0.00150 \times \text { nest } \\
\text { availability })\end{array}$ & 0.128 & 0.618 & 0.437 \\
\hline & & $\begin{array}{l}\text { Spot density (No. of spots/ } \\
\mathrm{mm}^{2} \text { ) }\end{array}$ & $\begin{array}{l}\text { Spot density }=0.679-(0.0108 \times \text { nest } \\
\text { availability })\end{array}$ & 0.353 & 5.255 & 0.028 \\
\hline & & Spot coverage (\%) & $\begin{array}{l}\text { Spot coverage }=18.364-(0.0349 \times \text { nest } \\
\text { availability })\end{array}$ & 0.0475 & 0.0837 & 0.774 \\
\hline & \multirow[t]{4}{*}{ Blunt } & Spot size $\left(\mathrm{mm}^{2}\right)$ & $\begin{array}{l}\text { Spot size }=0.0955+(0.000157 \times \text { nest } \\
\text { availability })\end{array}$ & 0.0171 & 0.0109 & 0.918 \\
\hline & & $\begin{array}{l}\text { Spot density (No. of spots/ } \\
\mathrm{mm}^{2} \text { ) }\end{array}$ & $\begin{array}{l}\text { Spot density }=0.721-(0.0124 \times \text { nest } \\
\text { availability })\end{array}$ & 0.446 & 9.207 & 0.004 \\
\hline & & Spot coverage (\%) & $\begin{array}{l}\text { Spot coverage }=12.079-(0.127 \times \text { nest } \\
\text { availability })\end{array}$ & 0.227 & 2.004 & 0.165 \\
\hline & & Spot distribution & $\begin{array}{l}\text { Spot distribution }=11.586-(0.124 \times \text { nest } \\
\text { availability })\end{array}$ & 0.219 & 1.867 & 0.18 \\
\hline \multirow[t]{10}{*}{ The whole clutch assessment } & \multirow[t]{3}{*}{ Side } & Spot size $\left(\mathrm{mm}^{2}\right)$ & $\begin{array}{l}\text { Spot size }=0.191-(0.00141 \times \text { nest } \\
\text { availability })\end{array}$ & 0.0912 & 0.31 & 0.581 \\
\hline & & $\begin{array}{l}\text { Spot density (No. of spots/ } \\
\mathrm{mm}^{2} \text { ) }\end{array}$ & $\begin{array}{l}\text { Spot density }=0.522-(0.00642 \times \text { nest } \\
\text { availability })\end{array}$ & 0.411 & 7.534 & 0.009 \\
\hline & & Spot coverage (\%) & $\begin{array}{l}\text { Spot coverage }=12.154-(0.127 \times \text { nest } \\
\text { availability })\end{array}$ & 0.269 & 2.886 & 0.098 \\
\hline & \multirow[t]{3}{*}{ Sharp } & Spot size $\left(\mathrm{mm}^{2}\right)$ & $\begin{array}{l}\text { Spot size }=0.0700+(0.0000734 \times \text { nest } \\
\quad \text { availability })\end{array}$ & 0.015 & 0.0083 & 0.928 \\
\hline & & $\begin{array}{l}\text { Spot density (No. of spots/ } \\
\mathrm{mm}^{2} \text { ) }\end{array}$ & $\begin{array}{l}\text { Spot density }=0.775-(0.0114 \times \text { nest } \\
\text { availability })\end{array}$ & 0.268 & 2.87 & 0.099 \\
\hline & & Spot coverage (\%) & $\begin{array}{l}\text { Spot coverage }=11.563-(0.0948 \times \text { nest } \\
\text { availability })\end{array}$ & 0.115 & 0.496 & 0.486 \\
\hline & \multirow[t]{4}{*}{ Blunt } & Spot size $\left(\mathrm{mm}^{2}\right)$ & $\begin{array}{l}\text { Spot size }=0.177+(0.00106 \times \text { nest } \\
\text { availability })\end{array}$ & 0.0892 & 0.297 & 0.589 \\
\hline & & $\begin{array}{l}\text { Spot density (No. of spots/ } \\
\mathrm{mm}^{2} \text { ) }\end{array}$ & $\begin{array}{l}\text { Spot density }=0.588-(0.00799 \times \text { nest } \\
\text { availability })\end{array}$ & 0.321 & 4.261 & 0.046 \\
\hline & & Spot coverage (\%) & $\begin{array}{l}\text { Spot coverage }=19.542-(0.0802 \times \text { nest } \\
\text { availability })\end{array}$ & 0.108 & 0.441 & 0.511 \\
\hline & & Spot distribution & $\begin{array}{l}\text { Spot distribution }=0.412+(0.0131 \times \text { nest } \\
\text { availability })\end{array}$ & 0.203 & 1.593 & 0.215 \\
\hline
\end{tabular}

A total of $38 \mathrm{DFs}$ were used in the analysis

Although this NPM model has recently been recommended and the granularity filtering approach pattern processing used (e.g. Spottiswoode and Stevens 2010; Stoddard and Stevens 2010; Spottiswoode and Stevens 2012; Stoddard et al. 2014; Caves et al. 2015; Medina et al. 2016), spot measurement is still a commonly used approach (Gosler et al. 2000; Antonov et al. 2012). Third, we used a larger sample size $(n=39)$ than either of these two studies ( $n=20$ : Antonov et al. 2012 and $n=30$ : Yang et al. 2016) and thus our result should be statistically more robust. Finally, as suggested in a study by Liang et al. (2016), one of the most important factors determining the choice of egg-laying strategy is the rate at which a cuckoo encounters a host nest. The local parasitism rate, nest site distribution and host behavior could all be related to the accessibility of the host nest and cuckoohost-nest encounter rate. At the site where we carried out the experiment, the parasitism rate was found to be $16.9 \%$, compared to $65.5 \%$ in the case of Yang et al. (2016). A higher parasitism rate means a shortage of available nests to be parasitized, which may translate into a smaller opportunity for the cuckoo to select the nest during the 
process of parasitism. A lack of selection opportunity is also evident in the study by Antonov et al. (2012), since the Marsh Warbler nests were sparsely distributed and most were also inconspicuous to the cuckoos, thus compromising their nest selection based on egg-spot matching. By reviewing all previous empirical data (Additional file 5: Table S2), we found that these factors could well explain almost all inferences drawn by earlier studies. All published data supporting the EMH were gathered from noisy hosts, which have a relatively low parasitism rate, i.e., between 11.3 and 31.1\% (Avilés et al. 2006; Honza et al. 2014), except for the study by conducted by Cherry et al. (2007), in which a parasitism rate of $64 \%$ was recorded, but these authors did not use the paired design to test the egg-matching between natural parasitized nests and non-parasitized nests. All other empirical data in support of the REH can either be explained by relatively high parasitism rates (Yang et al. 2016) or is due to the inconspicuous behavior of the hosts, which limits the opportunity for the cuckoo to select the best nest (Antonov et al. 2012; Yang et al. 2015a, b).

Except for the partially clear spot matching between cuckoo egg and the egg of its chosen host mentioned earlier, we also found that the spot density contrast between cuckoo and host eggs in the parasitized nests displayed significant negative correlation with the number of available host nests. This implied that the eggmatching egg-laying strategy of cuckoos could also vary and may change with fluctuations in the temporal availability of host nests. The effect of breeding synchronization among the host on the risk of cuckoo parasitism and nest-searching strategy has been reported (e.g. Jelínek et al. 2014; Soler et al. 2015), but our result provided evidence for the effect of breeding synchronization among the hosts on the egg-matching laying strategy adopted by cuckoos. This result further implied that the laying strategy could be fine-tuned in a relatively short period within one breeding season.

Another important factor that could also affect the egg-matching egg-laying strategy of the cuckoo is the egg rejection ability of host as suggested by Liang et al. (2016). The Oriental Reed Warbler, which is similar to its sister, the Great Reed Warbler of Europe, displays relatively high egg discrimination towards cuckoo eggs (Lotem et al. 1995; Moskát and Honza 2002; Li et al. 2016). However, the cognitive signature (either from the background color or/and egg spot) involved in the recognition process is not clearly understood. Although egg color has been shown to play an essential role (Moskát et al. 2008; Spottiswoode and Stevens 2010; Yang et al. 2010), several previous studies have reported that egg spots are more important than other egg phenotypes (e.g., egg color) for self recognition and for distinguishing non-self eggs (López-de-Hierro and Moreno-Rueda 2010; Stoddard and Stevens 2010; Stoddard et al. 2014). In our case, we found that egg rejection by warblers was as high as $78.3 \%$ when the warbler eggs were artificially painted with ten extra spots. Although the spots deliberately painted on the egg could not represent the natural spot pattern of the egg, this manipulation is commonly used to test the effect of egg patterns on egg rejection by warbler hosts (Hauber et al. 2006; Moskát et al. 2008, 2014). Therefore, our study clearly confirms that egg-spot patterns play an important role in egg rejection by the Oriental Reed Warbler, consequently leading to high selection pressure for the cuckoo to evolve a better matching egg-laying strategy.

Several aspects of the egg-spot pattern were considered in our egg spot-matching experiments, i.e., spot size, spot density, spot coverage and spot distribution. Except for spot coverage, which showed somewhat lower matching, the rest showed significant matching, either in the single egg or in the clutch analysis (Fig. 2; Additional file 3: Fig. S2). Furthermore, matching between cuckoo and warbler eggs appeared to occur on the side of the egg rather than on either end of the egg. Since the position of the egg inside the nest is such that the most exposed surface of the egg is the side (Polačiková et al. 2013), it becomes clear that matching on the side of the egg is more important to ensure the successful egg-laying strategy of cuckoo. However, other investigations have found that spot patterns on the blunt end of the egg constitute an important egg-pattern signature (Polačiková et al. 2007, 2010; Polačiková and Grim 2010). In the case of cuckoo eggs, the overall spot pattern on the blunt end exhibited lower matching with patterns on the blunt end of warbler eggs (Additional file 6: Supplementary Document 1). However, the eggs of both species have a relatively high spot density on the blunt end, thus making it difficult for the warbler to distinguish any differences in spot sizes on the non-self egg (Stoddard et al. 2014).

In conclusion, we demonstrated that the Common Cuckoo egg-laying matching in egg-spot pattern varied depending on the temporal availability of host nests. We propose that the host selection strategy of the Common Cuckoo probably involves both egg-phenotype matching and non-matching, not only in a parasitism system in which egg phenotypes exhibit polymorphism (Liang et al. 2016), but also in a parasitism system that exhibits continuous inter-clutch egg phenotypes. The choice which strategy to use may largely depend on both the condition of the environment (e.g., nest availability and conspicuousness) and egg rejection by the host. 


\section{Additional files}

Additional file 1: Figure S1. Picture showing an Oriental Reed Warbler nest in which ten extra dark brown spots for the egg recognition experiment were added to one random egg.

Additional file 2: Table S1. Local parasitism rate and number of parasitized nests that were successfully paired with their nearby nonparasitized nests for egg-spot assessment.

Additional file 3: Figure S2. Comparisons of egg spot contrasts between cuckoo and host eggs for all-eggs-assessments in the parasitized and nearest non-parasitized nests. The plots show the medians, quartiles, 5th and 95th percentiles of the spot contrasts.

Additional file 4: Figure S3. Correlation between egg-spot matching (between cuckoo and the warbler eggs) in parasitized nests and availability of host nests, synchronized with cuckoo egg-laying. The data are the spot contrasts on the whole clutch assessment. The solid and dashed lines show linear regressions and their 95\% confidence intervals, respectively.

Additional file 5: Table S2. Summary of the published data for the empirical testing of the egg-matching hypothesis.

Additional file 6: Supplementary Document 1. Comparison of eggspot parameters between cuckoo and warbler eggs from parasitized and non-parasitized nests.

\section{Authors' contributions}

$D L, Y R, D W, Z Z$ designed the experiments. DL, YW participated in the field work and data analysis. DL and YR wrote the manuscript and AKC helped to improve the structure and language of the manuscript. All authors have read and approved the final manuscript.

\section{Author details}

1 Provincial Key Laboratory of Animal Resource and Epidemic Disease Prevention, College of Life Sciences, Liaoning University, Shenyang 110036, People's Republic of China. ${ }^{2}$ Ministry of Education Key Laboratory for Biodiversity Science and Ecological Engineering, College of Life Sciences, Beijing Normal University, Beijing 100875, People's Republic of China.

\section{Acknowledgements}

This work was supported by the National Natural Science Foundation of China (Nos. 31301888 and 31672316 to DL), the General Scientific Research Project of the Education Department of Liaoning Province (L2015196 to DL) and the Open Fund of the Ministry of Education Key Laboratory for Biodiversity Sciences and Ecological Engineering, Beijing Normal University (K1401 to DL). We are grateful to two anonymous referees for constructive comments that significantly improved the manuscript. We would like to thank Yuxiang Li and Changbo Fu from the Liaohe Delta National Nature Reserve Management Bureau for their permission to undertake this study. We are also grateful to Elyse lemola, Lei Zhang, Hongwei Wei, Xinghai Sun, Qingbin Wang and Long Guo for their assistance in the fieldwork.

\section{Competing interests}

The authors declare that they have no competing interests.

\section{Ethical standards}

The experiments complied with the current laws of China. Experimental procedures were in agreement with the Animal Research Ethics Committee of the Liaoning Provincial Education Centre for Ecology and Environment, Liaoning University (No. 2013003).

Received: 5 August 2016 Accepted: 9 November 2016

Published online: 21 November 2016

\section{References}

Antonov A, Stokke BG, Fossøy F, Ranke PS, Liang W, Yang C, Moksnes A, Shykoff J, Røskaft E. Are cuckoos maximizing egg mimicry by selecting host individuals with better matching egg phenotypes? PLoS ONE. 2012;7:e31704.
Avilés J, Møller AP. How is host egg mimicry maintained in the cuckoo (Cuculus canorus)? Biol J Linn Soc. 2004:82:57-68.

Avilés JM, Stokke BG, Moksnes A, Røskaft E, ÅSmul A, Møller AP. Rapid increase in cuckoo egg matching in a recently parasitized reed warbler population. J Evol Biol. 2006;19:1901-10.

Avilés JM, Vikan JR, Fossøy F, Antonov A, Moksnes A, Røskaft E, Shykoff JA, Møller AP, Stokke BG. Egg phenotype matching by cuckoos in relation to discrimination by hosts and climatic conditions. Proc R Soc B: Biol Sci. 2012;279:1967-76.

Brooke MDL, Davies NB. A failure to demonstrate host imprinting in the cuckoo (Cuculus canorus) and alternative hypotheses for the maintenance of egg mimicry. Ethology. 1991;89:154-66.

Brooke ML, Davies NB. Egg mimicry by cuckoos Cuculus canorus in relation to discrimination by hosts. Nature. 1988;335:630-2.

Caves EM, Stevens M, Iversen ES, Spottiswoode CN. Hosts of avian brood parasites have evolved egg signatures with elevated information content. Proc R Soc B Biol Sci. 2015;282:20150598.

Chance EP. The truth about the cuckoo. London: Country Life Ltd.; 1940.

Cherry MI, Bennett ATD, Moskát C. Do cuckoos choose nests of great reed warblers on the basis of host egg appearance? J Evol Biol. 2007;20:1218-22.

Davies N, Brooke MDL. Cuckoos versus reed warblers: adaptations and counteradaptations. Anim Behav. 1988;36:262-84.

Davies NB. Cuckoos, cowbirds and other cheats. London:T \& AD Poyser; 2000.

Davies NB. Cuckoo adaptations: trickery and tuning. J Zol. 2011;284:1-14.

Feeney WE, Welbergen JA, Langmore NE. The frontline of avian brood parasitehost coevolution. Anim Behav. 2012:84:3-12.

Feeney WE, Welbergen JA, Langmore NE. Advances in the study of coevolution between avian brood parasites and their hosts. Annu Rev Ecol Evol Syst. 2014:45:227-46.

Fossøy F, Antonov A, Moksnes A, Røskaft E, Vikan JR, Møller AP, Shykoff JA, Stokke BG. Genetic differentiation among sympatric cuckoo host races: males matter. Proc R Soc B Biol Sci. 2011;278:1639-45.

Fossøy F, Sorenson MD, Liang W, Ekrem T, Moksnes A, Moller AP, Rutila J, Roskaft E, Takasu F, Yang C, Stokke BG. Ancient origin and maternal inheritance of blue cuckoo eggs. Nat Commun. 2016;7:10272. doi:10.1038/ ncomms 10272

Gibbs HL, Sorenson MD, Marchetti K, Brooke MDL, Davies NB, Nakamura H. Genetic evidence for female host-specific races of the common cuckoo. Nature. 2000;407:183-6.

Gosler AG, Barnett PR, Reynolds SJ. Inheritance and variation in eggshell patterning in the great tit Parus major. Proc R Soc B: Biol Sci. 2000;267:2469-73.

Grim T. Why is mimicry in cuckoo eggs sometimes so poor? J Avian Biol. 2002;33:302-5.

Hauber ME, Moskát C, Bán M. Experimental shift in hosts'acceptance threshold of inaccurate-mimic brood parasite eggs. Biol Lett. 2006;2:177-80.

Honza M, Moksnes A, Røskaft E, Stokke B. How are different common cuckoo Cuculus canorus egg morphs maintained? An evaluation of different hypotheses. Ardea. 2001;89:341-52.

Honza M, Šulc M, Jelínek V, Požgayová M, Procházka P. Brood parasites lay eggs matching the appearance of host clutches. Proc R Soc B Biol Sci. 2014;281:20132665.

Honza M, Taborsky B, Taborsky M, Teuschl Y, Vogl W, Moksnes A, Røskaft E. Behaviour of female common cuckoos, Cuculus canorus, in the vicinity of host nests before and during egg laying: a radiotelemetry study. Anim Behav. 2002;64:861-8.

Igic B, Cassey P, Grim T, Greenwood DR, Moskát C, Rutila J, Hauber ME. A shared chemical basis of avian host-parasite egg colour mimicry. Proc R Soc B Biol Sci. 2011;279:1068-79.

Jelínek V, Procházka P, Požgayová M, Honza M. Common Cuckoos Cuculus canorus change their nest-searching strategy according to the number of available host nests. Ibis. 2014;156:189-97.

Kilner R. The evolution of egg colour and patterning in birds. Biol Rev. 2006;81:383-406

Kleven O, Moksnes A, Røskaft E, Rudolfsen G, Stokke BG, Honza M. Breeding success of common cuckoos Cuculus canorus parasitising four sympatric species of Acrocephalus warblers. J Avian Biol. 2004;35:394-8.

Landini G. 2011. Auto local threshold. http://fiji.sc/Auto_Local_Threshold. Accessed 27 Apr 2016.

López-de-Hierro MD, Moreno-Rueda G. Egg-spot pattern rather than egg colour affects conspecific egg rejection in the house sparrow (Passer domesticus). Behav Ecol Soc. 2010;64:317-24. 
Li D, Zhang Z, Grim T, Liang W, Stokke BG. Explaining variation in brood parasitism rates between potential host species with similar habitat requirements. Evol Ecol. 2016;30:905-23.

Liang G, Yang C, Wang L, Liang W. Variation in parasitism rates by Common Cuckoos among three populations of the Oriental Reed Warblers. Sichuan J Zool. 2014;33:673-7 (In Chinese).

Liang W, Yang C, Takasu F. Modeling the cuckoo's brood parasitic behavior in the presence of egg polymorphism. J Ethol. 2016;34:127-32.

Lotem A, Nakamura H, Zahavi A. Constraints on egg discrimination and cuckoo-host co-evolution. Anim Behav. 1995;49:1185-209.

Marchetti K, Nakamura H, Gibbs HL. Host-race formation in the common cuckoo. Science. 1998;282:471-2.

Medina I, Troscianko J, Stevens M, Langmore NE. Brood parasitism is linked to egg pattern diversity within and among species of Australian passerines. Am Nat. 2016:187:351-62.

Moksnes A, Røskaft E. Egg-morphs and host preference in the common cuckoo (Cuculus canorus): an analysis of cuckoo and host eggs from European museum collections. J Zool. 1995;236:625-48.

Moksnes A, Røskaft E, Braa AT, Korsnes L, Lampe HM, Pedersen HC. Behavioural responses of potential hosts towards artificial cuckoo eggs and dummies. Behaviour. 1991;116:64-89.

Moskát C, Honza M. European Cuckoo Cuculus canorus parasitism and host's rejection behaviour in a heavily parasitized Great Reed Warbler Acrocephalus arundinaceus population. Ibis. 2002;144:614-22.

Moskát C, Székely T, Cuthill IC, KisbenedekT. Hosts' responses to parasitic eggs: which cues elicit hosts' egg discrimination? Ethology. 2008;114:186-94.

Moskát C, Zölei A, Bán M, Elek Z, Tong L, Geltsch N, Hauber ME. How to spot a stranger's egg? A mimicry-specific discordancy effect in the recognition of parasitic eggs. Ethology. 2014;120:616-26.

Nakamura H, Miyazawa Y, Kashiwagi K. Behavior of radio-tracked Common Cuckoo females during the breeding season in Japan. Ornithol Sci. 2005;4:31-41.

Øien IJ, Moksnes A, Røskaft E. Evolution of variation in egg color and marking pattern in European passerines: adaptations in a coevolutionary arms race with the cuckoo Cuculus canorus. Behav Ecol. 1995;6:166-74.

Orians GH, Røskaft E, Beletsky LD. Do brown-headed cowbirds lay their eggs at random in the nests of red-winged blackbirds? Wilson Bull. 1989;101:599-605.

Payne RB. The ecology of brood parasitism in birds. Ann Rev Ecol Syst. 1977:8:1-28.

Polačiková L, Grim T. Blunt egg pole holds cues for alien egg discrimination: experimental evidence. J Avian Biol. 2010;41:111-6.

Polačiková L, Honza M, Procházka P, Topercer J, Stokke BG. Colour characteristics of the blunt egg pole: cues for recognition of parasitic eggs as revealed by reflectance spectrophotometry. Anim Behav. 2007;74:419-27.

Polačiková L, Stokke B, Procházka P, Honza M, Moksnes A, Røskaft E. The role of blunt egg pole characteristics for recognition of eggs in the song thrush (Turdus philomelos). Behaviour. 2010;147:465-78.

Polačiková L, Takasu F, Stokke B, Moksnes A, Røskaft E, Cassey P, Hauber M, Grim T. Egg arrangement in avian clutches covaries with the rejection of foreign eggs. Anim Cogn. 2013;16:819-28.

Rothstein SI. A model system for coevolution: avian brood parasitism. Ann Rev Ecol Syst. 1990;21:481-508.
Soler JJ, Aviles JM, Soler M, Møller AP. Evolution of host egg mimicry in a brood parasite, the great spotted cuckoo. Biol J Linn Soc. 2003;79:551-63.

Soler M. Long-term coevolution between avian brood parasites and their hosts. Biol Rev. 2014;89:688-704.

Soler M, Pérez-Contreras T, Soler JJ. Synchronization of laying by great spotted cuckoos and recognition ability of magpies. J Avian Biol. 2015;46:608-15.

Spottiswoode CN, Stevens M. Visual modeling shows that avian host parents use multiple visual cues in rejecting parasitic eggs. PNAS. 2010;107:8672-6.

Spottiswoode CN, Stevens M. Host-parasite arms races and rapid changes in bird egg appearance. Am Nat. 2012;179:633-48.

Stoddard MC, Kilner RM, Town C. Pattern recognition algorithm reveals how birds evolve individual egg pattern signatures. Nat Commun. 2014;5:4117.

Stoddard MC, Stevens M. Pattern mimicry of host eggs by the common cuckoo, as seen through a bird's eye. Proc R Soc B Biol Sci. 2010;277:1387-93.

Stoddard MC, Stevens M. Avian vision and the evolution of egg color mimicry in the common cuckoo. Evolution. 2011;65:2004-13.

Stokke BG, Hafstad I, Rudolfsen G, Bargain B, Beier J, Bigas Campàs D, Dyrcz A, Honza M, Leisler B, Pap PL, Patapavičius R, Procházka P, SchulzeHagen K, Thomas R, Moksnes A, Pape Møller A, Røskaft E, Soler M. Host density predicts presence of cuckoo parasitism in reed warblers. Oikos. 2007;116:913-22

Šulc M, Procházka P, Capek M, Honza M. Common cuckoo females are not choosy when removing an egg during parasitism. Behav Ecol. 2016. doi:10.1093/beheco/arw08.

Underwood TJ, Sealy SG. Parameters of brown-headed cowbird Molothrus ater egg discrimination in warbling vireos Vireo gilvus. J Avian Biol. 2006;37:457-66.

Wyllie I. The cuckoo. London: Batsford; 1981.

Yang C, Li D, Wang L, Liang G, Zhang Z, Liang W. Geographic variation in parasitism rates of two sympatric cuckoo hosts in China. Zool Res. 2014;35:67-71.

Yang C, Huang Q, Wang L, Jiang A, Stokk BG, Fossøy F, Tunheim OH, Røskaft E, Liang W, Møller AP. Plaintive cuckoos do not select tailorbird hosts that match the phenotypes of their own eggs. Behav Eocl. 2015a;138:275-9.

Yang C, Liang W. The role of blinded methods in the studies of animal behavior. Chin J Zool. 2016;51:663-7 (In Chinese)

Yang C, Liang W, Cai Y, Shi S, Takasu F, Møller AP, Antonov A, Fossøy F, Moksnes A, Røskaft E, Stokke BG. Coevolution in action: disruptive selection on egg colour in an avian brood parasite and its host. PLoS ONE. 2010;5:e10816.

Yang C, Takasu F, Liang W, Moller A. Why cuckoos should parasitize parrotbills by laying eggs randomly rather than laying eggs matching the egg appearance of parrotbill hosts? Avian Res. 2015b;6:5.

Yang C, Wang L, Liang W, Møller AP. Do common cuckoos (Cuculus canorus) possess an optimal laying behaviour to match their own egg phenotype to that of their Oriental reed warbler (Acrocephalus orientalis) hosts? Biol J Linn Soc. 2016;117:422-7.

\section{Submit your next manuscript to BioMed Central and we will help you at every step:}

- We accept pre-submission inquiries

- Our selector tool helps you to find the most relevant journal

- We provide round the clock customer support

- Convenient online submission

- Thorough peer review

- Inclusion in PubMed and all major indexing services

- Maximum visibility for your research

Submit your manuscript at www.biomedcentral.com/submit 